\title{
Prevalence of CRYPTOSPORIDIUM INFECTION IN GOATS MAINTAINED UNDER SEMI-EXTENSIVE FEEDING CONDITIONS IN THE SOUTHEAST OF SPAIN
}

\author{
SANZ CEBALLOS L.*, ILLESCAS GÓMEZ P.**, SANZ SAMPELAYO M.R.*, GIL EXTREMERA F.*
}

\& RODRÍGUEZ OSORIO M.*

\section{Summary:}

The aim of the present study was to estimate the prevalence of Cryptosporidium parvum infection in goats maintained under semiextensive feeding conditions in the southeast of Spain. Four farms took part in the study. Samples were obtained during the autumn and spring kidding seasons. The goats were divided into three groups: group | (0-15 days), group || (> 15 days-2 months) and group III (> 2 months-9 years). Faecal specimens were concentrated and smears of the sediment $(25 \mu \mathrm{l})$ were stained by the modified Ziehl-Neelsen acid fast technique. Parasite oocysts were identified in all the farms; of the 582 goats, 111 were found to have the parasite in their faeces, i.e. the prevalence was $19.1 \%$. The frequency distributions of the Cryptosporidium oocyst counts according to the age categories were $10.4 \%, 13.4 \%$ and $25.2 \%$ for groups I, II and III respectively. With respect to the kidding season, no differences were found. The present study revealed the high prevalence of Cryptosporidium infection in goats in the studied zone.

KEY WORDS : Cryptosporidium parvum, prevalence, goat, southeast of Spain.

F or arid and semi-arid regions of the Mediterranean zone, livestock farming based on extensive or semi-extensive feeding conditions is proposed as the option offering greatest productive possibilities. In this context, the goat is a species of choice because of its ability to adapt to these climatic conditions and thanks to the high value of caprine products, milk and meat (Boza, 2005). However, goats are among the farm animals that are most affected by cryptosporidiosis, and farmers suffer considerable financial losses on this account. Cryptosporidium infection may have an important economic impact on farmers because of high morbidity and sometimes high mortality rates among farm animals (Casemore et al., 1997). This mortality increases when

\footnotetext{
* Consejo Superior de Investigaciones Científicas, Estación Experimental del Zaidín, Unidad de Nutrición Animal, Profesor Albareda, 1. 18008 Granada, Spain.

** Laboratorio de Producción Animal. Junta de Andalucía. Granada, Spain.

Correspondance: Matilde Rodríguez Osorio.

Tel.: +34 958572757 - Fax: +34958 572753 .

E-mail: mrosorio@eez.csic.es
}

Résumé : Prévalence de LA CRYPTOSPORIDIOSE CAPRINE CHEZ LES ANIMAUX ÉLEVÉS EN SEMI-EXTENSIF DANS LE SUD-EST DE L'ESPAGNE Cette étude avait pour objectif de déterminer la prévalence de la cryptosporidiose caprine chez les animaux élevés en semi-liberté dans le sud-est de l'Espagne. Elle a porté sur quatre exploitations. Des échantillons ont été obtenus pendant les chevrotages d'automne et de printemps. Les chèvres ont été réparties en trois groupes d'âge: groupe | (0-75 jours), groupe || |> 15 jours2 mois) et groupe III (> 2 mois-9 ans). Ces échantillons fécaux ont été concentrés et les frottis $(25 \mu)$ ont été colorés par la technique de Ziehl-Neelsen modifiée. Le parasite a été détecté dans toutes les exploitations; les fèces de 117 chèvres sur 582 contenaient le parasite, soit une prévalence de 19,1\%. La distribution de la fréquence du taux d'oocystes de Cryptosporidium en fonction des catégories d'âge était de 10,4\%, 13,4\% et 25,2\% pour les groupes I, II et III respectivement. Concernant la période du chevrotage, aucune différence n'a été trouvée. Cette recherche a révélé la prévalence élevée de cryptosporidiose caprine dans la région étudiée.

MOTS CLÉS : Cryptosporidium parvum, prévalence, chèvre, sud-est de l'Espagne.

the disease in associated with concurrent infections or deficiencies in nutrition or husbandry (de Graaf et al., 1999). Moreover, Cryptosporidium oocysts excreted with the faeces of infected farm animals can be a source of human infection, and there is a high incidence of the disease in AIDS patients, against which there is no consistently effective treatment (Tzipori, 1998). In goats, infection was first described in Australia in a 2-week-old kid with diarrhoea (Mason et al., 1981). Since then, the infection has been diagnosed in outbreaks of diarrhoea and prevalence in goat kids has been reported in several European countries (Majewska et al., 2000).

In Spain Cryptosporidium infection in small ruminants was first diagnosed in 1985 (Rojo Vázquez et al., 1985); subsequently, cryptosporidiosis was reported from different geographical areas (Rojo Vázquez et al., 1987; Matos-Fernández et al., 1993; Castro-Hermida et al., 2007). Taking into account this background and its relevance, the aim of the present study was to estimate the prevalence in relation to age and kidding season of Cryptosporidium infection in goats at randomly selected farms in the southeast of Spain. 


\section{MATERIALS AND METHODS}

\section{STUDY AREA}

T The study was carried out at four commercial goat farms in the province of Almería (southeast of Spain). Farms1 and 2 are located in Nijar and Tabernas, respectively, an area with mild temperatures where the average annual rainfall does not exceed $200 \mathrm{~mm}$. Farms 3 and 4 are in the area known as Los Velez, a colder, slightly less dry area with an average annual rainfall of $350 \mathrm{~mm}$. Within each one of the above area, one farm was selected based on its deficiencies in nutrition and husbandry, the other presenting excellent practices in this respect.

\section{ANIMALS, EXPERIMENTAL DESIGN AND PROCEDURE}

The animals were of the Murciano-Granadina and Malagueña breeds. The total number of animals per farm and the corresponding population densities were as follows: 400 and 0.27 animals $/ \mathrm{m}^{2}$ for farm 1, 250 and 0.48 animals $/ \mathrm{m}^{2}$ for farm 2,350 and 0.47 animals $/ \mathrm{m}^{2}$ for farm 3 and, 300 and 0.55 animals $/ \mathrm{m}^{2}$ for farm 4 . To obtain samples, every farm was visited twice during the study period (September 2004-April 2005). A total of 582 faecal samples were examined using a morphologic technique. The samples were obtained during 2004 and 2005, during the periods corresponding to the spring (March-April) and autumn (SeptemberOctober) kidding seasons at each farm. Within each farm, the goats were divided into three groups according to their age: group I ( $0-15$ days), group II ( $>15$ days2 months) and group III (> 2 months-9 years). On average, $20 \%$ of these animals were of the first age, and $60 \%$, of the third. When the samples were taken, the second age was less commonly represented on the four farms, due to the fact that these animals are sold at this age (especially the males) for slaughter. In order to achieve one representative sample of the total population and thus deduce statistically valid results, in each group, more than $10 \%$ of the animals were sampled. The samples were collected from randomly selected animals, and directly from the rectum, using sterile plastic gloves (second and third age) or sterile rectal swabs (first age). For each animal, the sampling date, origin, age and identification number were recorded. The samples were transported to the laboratory in a cool box and then stored for a maximum of $24 \mathrm{~h}$ before analysis. Faecal specimens, $1 \mathrm{~g}$ or $0.3 \mathrm{~g}$ in the case of those obtained using rectal swabs, were emulsified (10\% neutral buffered formalin), filtered through a set of two sieves (mesh size, $150 \mu \mathrm{m}$ and $45 \mu \mathrm{m}$ ), shaken vigorously with diethyl ether $(1 / 1, \mathrm{vol} / \mathrm{vol})$ and centrifuged at $1,000 \mathrm{~g}$ for $5 \mathrm{~min}$. The resulting top three layers were discarded. Smears of the sediment
$(25 \mu \mathrm{l})$ were stained on glass slides using the modified Ziehl-Neelsen acid fast technique (Henriksen \& Pohlenz, 1981). The entire surface of the smears (size $5.0 \mathrm{~cm} \times 2.4 \mathrm{~cm}$ ) was observed under an oil immersion lens $(1,000 \times)$. Infection intensity was semi-quantitatively evaluated: negative (absence of oocysts), few (one-two oocysts per field), many (over two oocysts per field) (Causapé et al., 2002).

\section{STATISTICAL ANALYSIS}

In order to identify the most interesting differences, a comparison was made, for the same farm and kidding season, of the values corresponding to the different ages. In the same way, we compared, for a given age and kidding season, the farm-related values. Finally, we compared, for a given farm and age, the values per kidding season. In addition, a global analysis was made of the values corresponding to each farm, age and kidding season. This analysis was performed using the equal percentages test developed by Sokal \& Rohlf (1979).

\section{RESULTS}

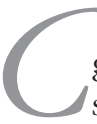
Tryptosporidium was identified in 111 of the 582 goats, and thus the prevalence was $19.1 \%$. The semi-quantitative evaluation showed that most of the infected animals of the first and second age, excreted many oocysts, although few oocysts were detected in the animals of the third age. Table I shows the results corresponding to each farm, by age and kidding season. At farms 1, 2 and 4, the ages most affected by parasite infection were the first and/or the third. Farm 3 presented, anomolously, a very low value for parasite infection for the first age and for the spring kidding season. In general, and with the exception of the values for the third age and farm 4, those detected during the spring kidding season were higher than those found during the autumn. Analysis of the results per farm, independently of the age and kidding season, showed that the values for farms 2 (26.2\%) and $4(26.5 \%)$ were higher $(\mathrm{p}<0.05)$ than those for farm $1(10.1 \%)$, but not significantly different from those for farm $3(15.5 \%)$. With respect to the age of the animals, and independently of the farm and kidding season, the highest value was for the third age $(25.0 \%)$, which was significantly different $(p<0.05)$ from those for the first $(10.4 \%)$ and second (14.6\%) ages; these latter two values did not vary significantly ( $p>0.05$ ). Finally, considering the values corresponding to the two sampling periods ( $17.8 \%$ spring kidding season versus $20.4 \%$ autumn kidding season), there was no statistically significant difference between them $(p<0.05)$. 


\begin{tabular}{ccccc}
\hline & Farm 1 & Farm 2 & Farm 3 & Farm 4 \\
\hline Age 1-S & $20.0 \%(2 / 10)^{\mathrm{a}, \mathrm{A},{ }^{*}}$ & $16.7 \%(3 / 18)^{\mathrm{a}, \mathrm{A},{ }^{*}}$ & $4.2 \%(1 / 24)^{\mathrm{a}, \mathrm{B},{ }^{*}}$ & $18.8 \%(3 / 16)^{\mathrm{a}, \mathrm{A}}$ \\
Age 2-S & $17.6 \%(3 / 17)^{\mathrm{a}, \mathrm{b}, \mathrm{A}, *}$ & $6.3 \%(1 / 16)^{\mathrm{b}, \mathrm{B}}$ & $20.8 \%(5 / 24)^{\mathrm{b}, \mathrm{A},{ }^{*}}$ & $20.7 \%(6 / 29)^{\mathrm{a}, \mathrm{A},{ }^{*}}$ \\
Age 3-S & $12.5 \%(5 / 40)^{\mathrm{b}, \mathrm{A}}$ & $19.2 \%(5 / 26)^{\mathrm{a}, \mathrm{A},{ }^{*}}$ & $16.7 \%(7 / 42)^{\mathrm{b}, \mathrm{A}}$ & $31.7 \%(13 / 41)^{\mathrm{b}, \mathrm{B}}$ \\
Age 1-A & $0 \%(0 / 24)^{\mathrm{a}, \mathrm{A},{ }^{*}}$ & $0 \%(0 / 17)^{\mathrm{a}, \mathrm{A},{ }^{*}}$ & $18.8 \%(3 / 16)^{\mathrm{a}, \mathrm{B},,^{*}}$ & $22.2 \%(2 / 9)^{\mathrm{a}, \mathrm{B}}$ \\
Age 2-A & $0 \%(0 / 16)^{\mathrm{a}, \mathrm{A},{ }^{*}}$ & $10.0 \%(1 / 10)^{\mathrm{b}, \mathrm{A}}$ & $9.1 \%(2 / 22)^{\mathrm{b}, \mathrm{A},{ }^{*}}$ & $30.0 \%(3 / 10)^{\mathrm{a}, \mathrm{B},{ }^{*}}$ \\
Age 3-A & $12.2 \%(5 / 41)^{\mathrm{b}, \mathrm{A}}$ & $55.8 \%(24 / 43)^{\mathrm{c}, \mathrm{C},{ }^{*}}$ & $20.0 \%(8 / 40)^{\mathrm{a}, \mathrm{B}}$ & $29.0 \%(9 / 31)^{\mathrm{a}, \mathrm{B}}$ \\
\hline
\end{tabular}

Age 1, 2 and 3: 0-15 days, 15-60 days and 60 days-9 years.

S: spring kidding season; A: autumn kidding season.

$a, b, c$ Means within the same farm and kidding season affected by different letters differ $(\mathrm{p}<0.05)$.

$\mathrm{A}, \mathrm{B}, \mathrm{C}$, Means within the same age and kidding season affected by different letters differ $(\mathrm{p}<0.05)$.

Means within the same farm and age with* indicate a difference between the two kidding season $(\mathrm{p}<0.05)$.

Table I. - Prevalence results \% (positive samples/examined samples), for Cryptosporidium parvum in naturally infected goats in relation to farm, age and kidding season.

\section{DISCUSSION}

I $\mathrm{n}$ the geographical zone in question, this is the first study of the prevalence of cryptosporidiosis in 1 goats. There were found to be Cryptosporidium oocysts in $111(19.1 \%)$ of the 582 goats examined. The parasite was detected in all the farms included in the study, but especially in the first and third of the ages considered, a finding which is in line with those reported by other authors (Matos-Fernández et al., 1993; Llamas Trujillo et al., 1994; Castro-Hermida et al., 2007). According to the semi-quantitative analysis carried out, our results showed the infection intensity decreased with age, being this similar to that found in goats by Noorden et al. (2000). From an economic standpoint, although the most striking effect of the infection is the death of the newborn, it is also necessary to bear in mind the significant weight losses among affected animals, the expenses of veterinary assistance and the costs incurred in caring for the animals. All these factors have a negative effect on the livestock farmer's economy. According to the characteristics of the farms, and in view of the results obtained, the care of the animals' health and nutrition, as well as the hygienic conditions of the farms, are aspects that may have a significant influence on the prevention and transmission of the infection, as concluded previously (Goyena et al., 1997; de Graaf et al., 1999). The highest proportion of oocysts was found at farm 4 , and this farm was also where hygienic conditions were worst. With respect to age, the highest proportion of animals infected by the parasite was found among the animals aged between 60 days and nine years, these animals being asymptomatic. Indeed, the elimination of oocysts by asymptomatic adult carriers is one of the mechanisms that has been suggested to explain the persistence of the infection within the ruminants kept in livestock farms. These oocysts, excreted in small quantities, are capable of transmitting the infection to newborn, highly vulnerable animals; such oocysts would have a multiplier effect on environmental contamination, and thus have repercussions on the epidemiology of the disease (Noordeen et al., 2001). The high prevalence found among animals of the first age is in agreement with the findings of other researchers for kid goats of different breeds, although in the latter cases no difference was established by kidding season (Delafosse et al., 2006; Geurden et al., 2008).

Independently of the age and farm, we found no significant difference in prevalence with respect to kidding season, this result being in agreement with that reported by Noordeen et al. (2001). However, the values for the spring kidding season, especially for the first two ages, were in general higher than those corresponding to the autumn. We believe this difference might be associated with the environmental conditions present in each season.

At the production level, the kid goats of the Granadina breed born during the autumn are known to present a higher survival ability than those born during the spring (García Navarro et al., 2008), which could be related to the existence of a different degree of parasite infection depending on the kidding season. In addition, asymptomatic adult carriers constitute a high risk factor for humans, especially those with an immunodepressive disorder such as AIDS, due to its potential zoonotic effect (Tzipori, 1998).

In conclusion, the findings of the present study reveal a high prevalence of Cryptosporidium infection in goats in the studied zone. This species should be considered a major animal reservoir for other farm animals and humans.

\section{ACKNOWLEDGEMENTS}

Whis study was financially supported by the Consejería de Innovación, Ciencia y Empresa. Junta de Andalucía. Spain (Project: C03-171). 


\section{REFERENCES}

Boza J. Papel del ganado caprino en las zonas desfavorecidas, in: Proceedings of the XXX National and IX International Annual Meeting of the SEOC. Inaugural Conference. Granada, Spain, 2005.

Casemore D.P., Wright S.E. \& CoOp R.L. Cryptosporidiosis: human and animal epidemiology, in: Cryptosporidium and Cryptosporidiosis. Fayer R. (eds), CRC Press Boca Raton FL, 1997, 65-92.

Castro-Hermida J.A., Almeida A., GonzÁlez-Warleta M., Correira da Costa J., Rumbo-Lorenzo C. \& Mezo M. Occurrence of Cryptosporidium parvum in healthy adult domestic ruminants. Parasitology Research, 2007, 101, 1443-1448.

Causapé A.C., Quilez J., Sánchez-Acedo C., Del Cacho E. \& LÓPEZ-BERNARD F. Prevalence and analysis of potential risk factors for Cryptosporidium parvum infection in lambs in Zaragoza (northeastern Spain). Veterinary Parasitology, 2002, 104, 287-298.

de Graaf D.C., Vanopdembosch E., Ortega-Mora L.M., AbBasi H. \& PeEters J.F. A review of the importance of cryptosporidiosis in farm animals. International Journal for Parasitology, 1999, 29, 1269-1287.

Delafosse A., Castro-Hermida J.A., Baudry C., Ares-Mazás E. \& CHARTIER C. Herd-level risk factors for Cryptosporidium infection in dairy-goat kids in western France. Preventive Veterinary Medicine, 2006, 77, 109-121.

García Navarro M.C., Ramos Morales E., de la Torre Adarva G., Fernández Navarro J.R., Rodríguez Osorio M., Gil ExtreMERA F. \& SANZ SAMPELAYO M.R. Growth of pre-ruminant kid goats and the composition of carcass fat deposits: Effects of providing a PUFA-rich fat in the milk replacer and influence of the kidding season. Food Science and Technology International, 2008, 14 (Suppl. 5), 85-94.

Geurden T., Thomas P., Casaert S., Vercruysse J. \& ClaereBOUT E. Prevalence and molecular characterisation of Cryptosporidium and Giardia in lambs and goat kids in Belgium. Veterinary Parasitology, 2008, 155, 142-145.

Goyena M., Ortíz J.M. \& Alonso F.D. Influence of different systems of feeding in the appearance of cryptosporidiosis in goat kids. The Journal of Parasitology, 1997, 83, 11821185 .

Henriksen S.A. \& Pohlenz J. Staining of cryptosporidia by a modified Ziehl-Neelsen technique. Acta Veterinaria Scandinavica, 1981, 22, 594-596.

Llamas Trujillo R., Illescas Gómez P., Ardpy Del Hoyo L. \& Llamas CRuz A. Criptosporidiosis en ovinos y caprinos en la provincia de Granada. Anales de la Real Academia de Ciencias Veterinarias de Andalucía Oriental, 1994, 7, 255263.

Majewska A.C., Werner A., Sulima P. \& Luty T. Prevalence in sheep and goats bred on five farms in west-central region of Poland. Veterinary Parasitology, 2000, 89, 269-275.

Mason R.W., Hartley W.J. \& Til L. Instestinal cryptosporidiosis in a kid goat. Australian Veterinary Journal, 1981, 57, 386-388.

Matos-Fernández M.J., Pereira-Bueno J., Ortega-Mora L.M., Pilar-Izquierdo M., Ferre I. \& Rojo VÁzQuez F.A. Preva- lencia de la infección por Cryptosporidium parvum en corderos, cabritos y terneros en la provincia de León. Acta Parasitológica Portuguesa, 1993, 1, 211.

Noorden F., Rajapakse R.P.V.J., Faizal A.C.M., Horadagoda U.N. \& ARulkanthan A. Prevalance of Cryptosporidium infection in goats in selected locations in three agroclimatic zones of Srilamka. Veterinary Parasitology, 2000, 93, 95101.

Noordeen F., Maizal A.C.M., Rajapakse R.P.V.J., Horadagoda U.N \& ARULKanthan A. Excretion of Cryptosporidium oocysts by goats in relation to age and season in dry zone of Sri Lanka. Veterinary Parasitology, 2001, 99, 79-85.

Rojo VÁzquez F., Gass A. \& Alunda J.M. Denuncia en España de la criptosporidiosis ovina, in: Proceedings of IV Congreso Nacional de Parasitología. Tenerife, 1985, 166.

Rojo VÁzquez F., Gass A., IzQuierdo M. \& Ortiz Menéndez J.C. Estudio de la criptosporidiosis de los pequeños rumiantes (ovinos y caprinos) en España. Medicina Veterinaria, 1987, 4, 263-270.

Sokal R.R. \& RohlF F.J. Biometría. Principios y métodos estadísticos en la investigación biológica. H. Blume Ediciones, Madrid, 1979, pp 601-702.

TzIPORI S. Cryptosporidiosis: laboratory investigations and chemotherapy. Advances in Parasitology, 1998, 40, 187221.

Reçu le 4 février 2009 Accepté le 2 juillet 2007 